Paula BOAVENTURA ${ }^{1}$

Rosa OLIVEIRA ${ }^{2,3}$

Dina PEREIRA ${ }^{1}$

Paula SOARES ${ }^{1,2}$

José TEIXEIRA-GOMES ${ }^{1}$

${ }^{1}$ Institute of Molecular Pathology and Immunology of the University of Porto (IPATIMUP), Portugal

${ }^{2}$ Medical Faculty

University of Porto

Portugal

${ }^{3}$ Center for Research in Health

Technologies and Information Systems

(CINTESIS),

Porto, Portugal

Reprints: P. Soares

$<$ psoares@ipatimup.pt>

Article accepted on 12/18/2011

\section{Head and neck basal cell carcinoma prevalence in individuals submitted to childhood X-ray epilation for tinea capitis treatment}

\begin{abstract}
Background: A higher prevalence for basal cell carcinoma (BCC) has been associated with radiation, namely with tinea capitis epilation treatment. Objective: To evaluate the prevalence of head and neck basal cell carcinoma (BCC) and to identify the major risk factors for BCC in individuals irradiated in childhood for tinea capitis treatment. Methods: We clinically observed 1,308 individuals from an original cohort of 5,356 irradiated between 1950 and 1963, registering previous skin lesions excisions and proposing for surgery all the suspicious lesions detected. In 585 participants, 47 with $\mathrm{BCC}$, the skin pigmentation was measured. Results: The overall prevalence of BCC was $8.0 \%$ and of multiple $\mathrm{BCC}$ was $2.4 \%$. Both total (14.7\%) and multiple BCC (6.6\%) were significantly more common in the individuals who had received a higher radiation dose. Multiple BCC was more prevalent $(3.7 \%)$ in younger irradiated individuals and total BCC $(9.4 \%)$ in women. Participants with $\mathrm{BCC}$ and without $\mathrm{BCC}$ presented similar skin pigmentation. Conclusion: Younger age at irradiation, higher dose and female gender increased the risk of developing $\mathrm{BCC}$ in these irradiated individuals.
\end{abstract}

Key words: basal cell carcinoma, scalp irradiation, scalp ringworm, skin pigmentation, tinea capitis, $\mathrm{X}$-ray epilation
$\mathrm{T}$ inea capitis is a fungal disease that reached epidemic proportions in the 1950s and 1960s in Portugal, similarly to other European countries [1]. As there was no oral antifungal treatment available at that time, radiation-induced epilation was used as an efficient method for tinea capitis treatment and eradication [2, 3]. This procedure, performed according to the KienbockAdamson method, was considered, at that time, as theoretically without risks [2]. After epilation it was easier to apply the sulphur ointment and iodine tincture that were the advised therapeutic procedures [2].

Basal cell carcinoma (BCC) is the most common skin cancer $[4,5]$ and a higher prevalence has been associated with radiation [6], namely with the tinea capitis epilation treatment [7-9]. It is the most frequent tumour developing on irradiated scalps [10]. An increase in BCC risk with increased radiation dose has been observed [7] and an inverse association between age at exposure and BCC risk has also been referred [11, 12]. Radiation-induced BCC is more aggressive and more prone to recurrence so these patients should be under close observation [9]. Furthermore the risk for BCC is persistently elevated 40 or more years after the first treatment $[12,13]$.

We had access to the registries of these treatments performed between 1950 and 1963 in the Dispensário de Higiene Social do Porto (DHSP), an institution dedicated to infectious diseases that is now closed. These registries included name, address, age, treatment date, tinea diagnosis and dose received. Most of the patients were children.
Having in mind the association above referred between the radiation treatment they experienced and $\mathrm{BCC}$, we decided to perform a clinical follow-up study of these individuals in order to detect these neoplasias. Our primary objectives in the present work were to evaluate the prevalence of BCC and to identify the major correlates of BCC in these individuals.

\section{Material and methods}

The DHSP files included 5,356 individuals submitted to radiation-induced epilation between 1950 and 1963 and it was possible to trace $3,522(66 \%)$. This registration included name, address (at the time of the treatment), age, treatment date, tinea diagnosis and dose received. The majority of the individuals were 6-15 years old (70\%), which reflects the scholar inspections done at the time to diagnose the disease. The standard treatment was carried out according to the Kienbock-Adamson technique [2] using one X-ray epilation session (325-400 R), but $6 \%$ of the individuals were submitted to 2 or 3 sessions. Their present addresses were obtained by checking the entire cohort in the Portugal Telecom (National Phone Company) website and in National Health Service databases. A letter was sent to all the individuals for whom a presumed present address was found, informing them about the treatment they had been submitted to and inviting them to contact us. A free 
phone line was provided for that purpose. A second letter was sent whenever the first received no reply. Of the 3,522 presumably traced individuals, 1,308 agreed to be clinically observed (participants) and 287 were deceased. The clinical examination took place between March 2006 and November 2010. It included a summarized clinical history and a detailed examination of the head and neck areas in order to detect suspicious skin lesions. Skin colour (tanned/untanned) was registered. In 585 participants, 47 with $\mathrm{BCC}$, the melanin contents on the inner arm and on the forehead were measured with a DermaSpectrometer. A cervical ultrasound and a serum calcium measurement were also suggested (data not shown).

All the BCC lesions were confirmed through hospital or cancer registries (RORENO data base). A copy of the histological report of the excised lesions was requested from the pathology departments or directly from the patients. Using the information available in the histopathological reports, the following histological subtypes were considered: nodular BCC, superficial BCC, infiltrative BCC and basosquamous BCC $[14,15]$.

In the statistical analysis, prevalence estimates for each outcome were compared using chi-squared tests, with pvalues $<0.05$ considered significant for each survey. We used logistic regression to explore the determinants taking $\mathrm{BCC} /$ multiple $\mathrm{BCC}$ as the dependent variable and the risk factors as independent variables. These analyses tested whether the prevalence of BCC increased ( $p$ values $<0.05$ were considered statistically significant), taking into account the risk factors. Analyses of the BCC data were conducted using PASW Statistics for Windows (release 18.0; $\mathrm{IBM}^{\circledR}$, SPSS $^{\circledR}$ Statistics).

All the procedures were done under strict ethical and confidentiality procedures according with the Portuguese ethical rules. The study was approved by the Ethics Committee of the Hospital Pedro Hispano and all the participants signed an informed consent.

\section{Results}

The main characteristics of participants and total cohort individuals have been reported elsewhere [16]. There was a significant difference towards younger age at time of irradiation between participants and cohort members. This may be due to the long delay between the irradiation and the actual contact, which in some situations was more than 50 years. More of the individuals who were older at the time of irradiation may have deceased, are more frequently ill, or simply are less likely to come to a clinical observation after such a long time since irradiation. There was also a significant difference towards more women between participants and cohort members. A possible explanation is that women may be more likely to come to the clinical observation as they are more concerned about their health than men [17]. The mean age of participants ( \pm standard deviation) was 58.4 years $( \pm 4.4)($ median $=58)$.

We clinically observed 1,308 individuals from the original cohort, among whom 75 already had a BCC diagnosis. In our clinical observation, 146 participants presented suspicious undiagnosed head and neck lesions that were proposed for surgical excision, but only 87 had surgery
Table 1. Results from the 146 suggested excisions of skin lesions

\begin{tabular}{|lll|}
\hline & N & $(\%)$ \\
\hline Performed & 87 & $(59.6)$ \\
\hline Malignant tumour & 37 & $(25.3)$ \\
- BCC & 35 & $(24.0)$ \\
- Melanoma & 1 & $(0.7)$ \\
- Palate malignant tumour & 1 & $(0.7)$ \\
\hline Benign tumour & 46 & $(31.5)$ \\
- Actinic keratosis & 1 & $(0.7)$ \\
- Trichoblastoma & 1 & $(0.7)$ \\
- Trichoepithelioma & 3 & $(2.1)$ \\
- Nevi/papillomas/traumatic & 41 & $(28.1)$ \\
lesions/seborreic keratosis & & \\
\hline Not sent for histological analysis & 4 & $(2.7)$ \\
\hline Not Excised & 59 & $(40.4)$ \\
- Lesion disappeared & 4 & $(2.7)$ \\
- Patient refused excision & 11 & $(7.5)$ \\
- Different medical opinion & 17 & $(11.6)$ \\
- Waiting list for surgery & 11 & $(7.5)$ \\
- Without information & 16 & $(11.0)$ \\
\hline
\end{tabular}

(table 1). The remaining 59 had no surgery or biopsy for the reasons presented in Table 1. Of the 87 lesions excised, 35 were BCCs; 29 represented new BCC patients diagnosed by us, the other 6 had already had a previous BCC excision. Considering the retrospective and prospective evaluation of $\mathrm{BCC}$ lesions, we had 104 participants with $\mathrm{BCC}$ diagnosis, 30 men and 74 women. Concerning the number of lesions, 73 participants had only one BCC; and the other 31 had multiple lesions (30\%). Among participants with multiple BCCs, 19 had two tumours, 5 had three and 7 participants had four or more, leading to a total number of 165 BCC lesions in 104 participants. The mean number of lesions per patient was 1.82 . We also observed 4 participants with squamous cell carcinoma (SCC), previously diagnosed, and three with melanomas (one diagnosed in the present study). One hundred and fifty-nine BCCs $(96.4 \%)$ were localized on the head or neck. Ninety-nine BCCs developed on areas considered to be protected from the sun (scalp and trunk) (70.2\%) and 42 on areas considered as exposed to it (face and neck) (29.8\%), and for 24 cases the precise head or neck localization could not be determined. We could obtain 86 histological reports that presented information on the histological subtype (table 2). The other 79 BCCs were classified as "not defined", as the histological report did not present information about the subtype or was not available. The most common subtypes were nodular $(46.5 \%)$ and superficial (38.4\%). Nodular subtype was more common in sun-exposed areas when compared to the other subtypes, but the differences were not significant. Univariate analysis for gender, age at irradiation, age at diagnosis, irradiation dose, untanned/tanned skin (phototypes II and III), melanin content, tinea diagnosis variables was conducted but no significant association was found with BCC subtype.

The overall prevalence of BCC $(95 \% \mathrm{CI})$ was $8.0 \%$ (4.88.6) and of multiple BCC (95\% CI) was $2.4 \%$ (1.6-4.1). The mean age at excision of the first lesion $( \pm \mathrm{SD})$ was 54.3 years $( \pm 8.2)$. Univariate analysis for gender, age at irradiation, 
Table 2. BCC subtype distribution according to gender, age at diagnosis, localization and BCC frequency

\begin{tabular}{|c|c|c|c|c|c|c|}
\hline & $\begin{array}{l}\text { Nodular } \\
\text { n }(\%)\end{array}$ & $\begin{array}{l}\text { Superficial } \\
\mathbf{n}(\%)\end{array}$ & $\begin{array}{l}\text { Infiltrative } \\
\text { n }(\%)\end{array}$ & $\begin{array}{l}\text { Basosquamous } \\
\text { n }(\%)\end{array}$ & Not defined & Total \\
\hline \multicolumn{7}{|l|}{ Gender } \\
\hline - Men & $12(50)$ & $9(37.5)$ & $1(4.2)$ & $2(8.3)$ & 16 & 40 \\
\hline - Women & $28(45.2)$ & $24(38.7)$ & $6(9.7)$ & $4(6.5)$ & 63 & 125 \\
\hline Age at diagnosis $($ mean \pm SD) & $54.7 \pm 8.6$ & $53.1 \pm 9.1$ & $57.0 \pm 4.5$ & $52.8 \pm 9.4$ & $52.6 \pm 8.7$ & $54.3 \pm 8.2$ \\
\hline \multicolumn{7}{|l|}{ Localization } \\
\hline - Sun-protected area & $25(42.4)$ & $24(40.1)$ & $6(10.2)$ & $4(5.4)$ & 40 & 99 \\
\hline - Sun-exposed area & $11(55.0)$ & $6(30.0)$ & $1(5.0)$ & $2(10.0)$ & 22 & 42 \\
\hline - Not determined & $4(57.1)$ & $3(42.9)$ & 0 & 0 & 17 & 24 \\
\hline \multicolumn{7}{|l|}{ BCC frequency } \\
\hline - Single BCC & $18(42.9)$ & $16(38.1)$ & $5(11.9)$ & $3(7.1)$ & 31 & 73 \\
\hline - Mutiple BCC & $22(50.0)$ & $17(38.6)$ & $2(4.5)$ & $3(6.8)$ & 48 & 92 \\
\hline All & $40(46.5)$ & $33(38.4)$ & $7(8.1)$ & $6(7.0)$ & 79 & 165 \\
\hline
\end{tabular}

Table 3. Total BCC and multiple BCC prevalence and odds ratio (OR) in the 1308 participants according to gender, age at irradiation and irradiation dose

\begin{tabular}{|c|c|c|c|c|c|c|}
\hline & & Prevalence $(\%)$ & $\left(\% \mathrm{CI}_{95 \%}\right)$ & OR & $\left(\right.$ OR CI $\left.\mathrm{I}_{95} \%\right)$ & p-value \\
\hline \multicolumn{7}{|l|}{ Total BCC } \\
\hline \multirow[t]{2}{*}{ Gender } & - $\mathrm{M}$ & 5.7 & $(1.2-10.2)$ & & & \\
\hline & $\bullet \mathrm{F}$ & 9.4 & $(3.7-15.1)$ & 1.71 & $(1.11-2.66)$ & 0.015 \\
\hline \multirow{2}{*}{ Age at irradiation } & - $\leq 5$ years & 8.9 & $(3.3-14.5)$ & 1.21 & $(0.80-1.83)$ & 0.378 \\
\hline & - $>5$ years & 7.5 & $(2.3-12.7)$ & & & \\
\hline \multirow[t]{2}{*}{ Irradiation dose } & - $325-400 \mathrm{R}$ & 7.5 & $(2.3-12.7)$ & & & \\
\hline & - $\geq 630 \mathrm{R}$ & 14.7 & $(7.7-21.7)$ & 2.08 & $(1.06-4.09)$ & 0.029 \\
\hline \multicolumn{7}{|l|}{ Multiple BCC } \\
\hline \multirow{2}{*}{ Gender } & - $\mathrm{M}$ & 1.5 & $(0.0-5.9)$ & & & \\
\hline & $\bullet \mathrm{F}$ & 2.9 & $(0.0-8.9)$ & 1.94 & $(0.87-4.39)$ & 0.101 \\
\hline \multirow[t]{2}{*}{ Age at irradiation } & - $\leq 5$ years & 3.7 & $(0.0-10.5)$ & 2.24 & $(1.1-4.57)$ & 0.023 \\
\hline & - $>5$ years & 1.7 & $(0.0-7.9)$ & & & \\
\hline \multirow[t]{2}{*}{ Irradiation dose } & - $325-400 \mathrm{R}$ & 2.1 & $(0.0-7.3)$ & & & \\
\hline & - $\geq 630 \mathrm{R}$ & 6.6 & $(0.0-15.5)$ & 3.25 & $(1.21-8.71)$ & 0.013 \\
\hline
\end{tabular}

age at diagnosis, irradiation dose, untanned/tanned skin (phototypes II and III), melanin content, and tinea diagnosis variables was conducted and significant association was found concerning gender, age at irradiation and irradiation dose and BCC presence (table 3). No significant differences were found when multivariate analysis was performed. BCC was significantly more prevalent in women $(9.4 \%)$ than in men $(5.7 \%)$, with an increased risk to develop a BCC in women, OR (95\% CI) of 1.72 (1.11-2.66). We found a significantly higher total BCC and multiple BCC prevalence in the participants who received a dose $\geq 630 \mathrm{R}$, ( $14.5 \%$ and $6.6 \%$ respectively) when compared to the ones who received the $325-400 \mathrm{R}$ dose, $(7.5 \%$ and $2.1 \%$ respectively). The participants who received a higher dose were more likely to develop a BCC OR (95\% CI) of 2.08 (1.06$4.09)$, and more likely to develop a multiple BCC OR $(95 \%$ CI) of 3.25 (1.21-8.71). The individuals irradiated at a younger age were more likely to develop multiple BCC, OR (95\% CI) was 2.24 (1.10-4.57). The mean latency period for lesion excision was 47.2 years $( \pm 7.3)$. No significant differences were found in this latency period considering age at irradiation, irradiation dose and gender.
The majority of the participants were classified as phototypes II and III. Melanin content in unexposed (inner arm) and exposed (forehead) areas was similar in the participants who developed BCC when compared to the ones who did not develop BCC (table 4), showing normal distributions in both groups (figure 1).

\section{Discussion}

Radiation has been associated with a high prevalence of $\mathrm{BCC}$ [7-9]. In the present study we found a BCC prevalence of $8.0 \%$ in individuals irradiated in childhood for tinea capitis epilation treatment. Data concerning the prevalence of $\mathrm{BCC}$ in asymptomatic non-irradiated cohorts are scarce but present a low prevalence, ranging from $0.1 \%$ to $0.9 \%$ [1820]. In previous studies, using only retrospective data, scalp irradiation for tinea capitis during childhood resulted in a 3.6 to 4 fold increased risk of BCC [7, 12]. In our study, if we consider only the BCCs previously diagnosed, the rate of BCC was $5.7 \%$, a value that can be considered similar 


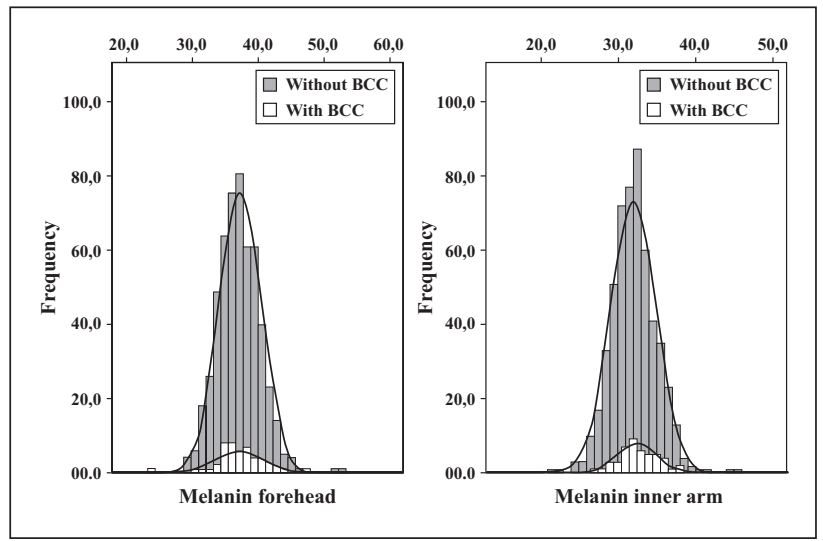

Figure 1. Melanin content distribution in the inner arm and in the forehead.

to the one found in the previous retrospective studies of similar cohorts referred above. In a small control group we are gathering (73 individuals to date; data not shown) constituted by age-matched, non-irradiated persons submitted to the same clinical protocol as the irradiated individuals, no suspicious skin lesions were found. Nevertheless, as we have only observed $24 \%$ of the entire cohort $(1,308 / 5,356)$ we cannot exclude a bias towards clinically observing more individuals with BCC, although $28 \%$ of the BCC cases were diagnosed by us in participants totally unaware of their problem. A bias in opposite direction (observing fewer $\mathrm{BCCs}$ than the ones really present) could also be present, due to the fact that $40 \%$ of the proposed skin lesion excisions were not performed. The mean age at excision of the first lesion found in our study, 54 years, (similar for both genders), was lower than the 64-65 years referred in previous non-irradiated cohorts (of 10,000-200,000 individuals $[20,21])$, but in accordance with the younger ages (39-56 years) found in other tinea capitis irradiated cohorts $[10,22-24]$. The mean latency period for lesion excision in the present study was 47 years. Maalej et al. [24] found a shorter latency period (36 years) in a similar tinea capitis cohort, defining the latency period as the time between irradiation and cancer occurrence. In our study we considered the latency period between irradiation and surgery, as it was not easy to be certain about the time of the cancer appearance. When excision was advised in our clinical observation, some patients referred to having lesions for several years. A shorter latency period was also referred in younger irradiated tinea capitis patients $[11,25]$. We did not find any significant differences in the latency period considering age at irradiation, irradiation dose and gender. The most common BBC lesion was the nodular subtype (46.5\%), followed by the superficial subtype (38.4\%). In other studies from non-irradiated individuals, nodular subtype was found to be the more common histological subtype, although with variable prevalence - 45 to $78 \%$ $[21,26-28]$. The value obtained in our series was similar to the one referred in the Hakverdi et al. [27] study but it was smaller than the values referred in the other studies. On the contrary, we had a higher prevalence of the superficial subtype. As the superficial subtype has been considered by several authors as high risk, due to its more aggressive behaviour [14,15], we supposed that this higher prevalence found in our study could be associated with the X-ray treat-
Table 4. Melanin content in the inner arm and the forehead of participants with BCC or without BCC

\begin{tabular}{|clllll|}
\hline & & Mean & (SD) & N & $(\%)$ \\
\hline Total BCC & & & & & \\
Inner arm & With lesion & 32.1 & $(2.5)$ & 47 & $(8.0)$ \\
& Without lesion & 32.0 & $(2.9)$ & 538 & $(92.0)$ \\
& & & & & \\
Forehead & With lesion & 37.4 & $(3.7)$ & 47 & $(8.0)$ \\
& Without lesion & 37.1 & $(3.1)$ & 536 & $(92.0)$ \\
& & & & & \\
Multiple BCC & & & & & \\
Inner arm & With lesion & 31.7 & $(2.7)$ & 14 & $(2.0)$ \\
& Without lesion & 32.0 & $(2.9)$ & 571 & $(98.0)$ \\
Forehead & With lesion & 37.8 & $(3.1)$ & 14 & $(2.0)$ \\
& Without lesion & 37.1 & $(3.2)$ & 569 & $(98.0)$ \\
\hline
\end{tabular}

SD: Standard Deviation; N: Count

ment. This is in accordance with our observation that the nodular subtype was more common in sun-exposed areas when compared to the other subtypes, although the differences were not significant. However, in the Mseddi et al. $[8,10]$ studies of tinea capitis irradiated patients, the superficial type was not mentioned while the nodular subtype appeared in 74-76\% of their cases. We cannot exclude, in our series, a possible bias due to the fact that the histological subtype was not defined in $47.9 \%$ of cases.

Higher radiation dose significantly increased BCC prevalence in our study (table 3 ) as would be expected. Karagas et al. [13] found an association between a history of radiation treatment and BCC that was particularly strong for $\mathrm{BCCs}$ arising within the radiation treatment field. Ron et al. [7] showed a dose response for BCC in their tinea capitis irradiated cohort. They also suggested that subsequent exposure to UV radiation would likely play a role in the expression of radiation-induced BCC [7].

Pigmentation characteristics, tendency to sunburn, and poor tanning ability, have all been associated with higher BCC risk $[29,30]$ although few studies have found epidemiological evidence. In our study we did not find a statistically significant association of these putative $\mathrm{BCC}$ risks factors since skin pigmentation and melanin content (non-exposed and exposed areas), were similar between the participants who developed BCC when compared to the ones who did not develop BCC. Although it was not possible to enrol all the participants in the skin melanin content analysis, the very similar values obtained for participants with BCC $v s$ participants without $\mathrm{BCC}$ indicate that this similarity will probably be maintained if we extend the analysis to all the participants. Taken together, these results also indicate that irradiation is a much stronger risk factor that masks the eventual (lower) risk given by skin pigmentation. The similar distribution pattern of melanin content found in the two groups leads us to suggest that, in this tinea capitis irradiation setting, skin pigmentation has minimal influence on $\mathrm{BCC}$ risk and that there is no additive or synergistic effect with irradiation.

We found that the odds ratio for multiple BCC, but not total $\mathrm{BCC}$, was significantly elevated for younger age at radiation. For total BCC, the OR increase was not statistically significant. Irradiation at young ages has been shown by 
other authors as increasing $\mathrm{BCC}$ risk [7, 12, 13], especially if radiation occurred in early childhood [7, 12]. Multiple $\mathrm{BCC}$ has been referred as more common in the BCC patients who suffered childhood scalp irradiation for tinea capitis treatment [9] and maybe considered as an index of individual susceptibility [12]. So we could argue that, in our study, the younger-irradiated children were more susceptible to the more aggressive form of the radio-induced lesion, multiple BCC. Multiple BCC was observed in the present study in $30 \%$ of the patients, a value roughly similar to the $38 \%$ found by Shore et al. [12] in tinea capitis irradiated individuals and much higher than the $16 \%$ found by Scrivener et al. [21] in their cohort of 10,245 non-irradiated BCC patients.

Incidence rates for $\mathrm{BCC}$ have been reported to be similar in both genders [20], higher in men [5] or higher in women [21]. Ron et al. [7], in their tinea capitis irradiated cohort, found a BCC relative risk for females slightly higher than for males, but without reaching significance. In our study, total BCC was significantly more common in women when compared to men and that still holds true if we consider only the previously diagnosed BCCs, suggesting that women show a higher susceptibility for BCC development in this setting. Considering multiple BCC, the prevalence for women remained higher than for men, but was no longer significant $(\mathrm{p}=0.101)$, possibly due to the lower figures of multiple BCC $(n=31)$. As more than half of the lesions found in women in our study (54\%) were present on the face and neck, we may speculate that women were more prone to having them removed, not only for health reasons, but also for aesthetic reasons.

Concerning skin malignancies other than BCC, we found 4 SCCs, previously diagnosed, and 3 melanomas, one diagnosed by us. The low figures obtained in our study for these lesions do not allow us to have a clear "picture". Nevertheless, Karagas et al. [6] initially suggested that exposure to therapeutic radiation was associated with $\mathrm{BCC}$ but not with SCC, and lately they have shown that early exposure to radiation treatment was a risk factor for SSC but not as strong as for BCC [13]. Shore et al. [12] found no association between ionizing radiation exposure and cutaneous malignant melanoma.

In summary, due to the high BCC prevalence found in these Portuguese tinea capitis irradiated individuals, and showing a higher risk for multiple BCCs in the younger irradiated ones, those who are younger at the present moment, we believe that this justifies a close follow-up of this cohort. This tumour, although causing low mortality, carries considerable morbidity [31]. We agree with Meibodi et al. [22], that it is very important to create awareness in these tinea capitis irradiated individuals and to refer them to their physician for any suspicious lesions, namely the dermatological ones.

Disclosure. Acknowledgments: We want to thank Prof. Sobrinho Simões for the valuable suggestions. The authors thank Ana Reis for proofreading. Gratefulness is also due to all the individuals that agreed to participate in this study as well as to all the physicians that provided us clinical information.

Prize ACS-MERCK SERONO in Cancer Epidemiology, 2010

Financial support: This work was supported by a grant from Calouste Gulbenkian Foundation (ref. 76636) and
FCT (project: PIC /IC /83154 /2007) and further funding from the Portuguese Foundation for Science and Technology (FCT), by a grant to P.B. (SFRH /BPD /34276 /2007). IPATIMUP is an Associate Laboratory of the Portuguese Ministry of Science, Technology and Higher Education and is partially supported by the FCT. The work was conducted with the support of Public Health Department of ARS-Norte.

Conflict of interest: none.

\section{References}

1. Esteves J. Algumas características etiológicas da endemia portuguesa de tinha. O Médico 1953 1: 831 -2.

2. Brandão. A roentgenterapia das tinhas do couro cabeludo (Aspectos técnicos e problemas). O Médico 1953; 1: 857-64.

3. Crossland PM. Therapy of tinea capitis; the value of $x$-ray epilation. Calif Med 1956; 84: 351-3.

4. Miller DL, Weinstock MA. Nonmelanoma skin cancer in the United States: incidence. J Am Acad of Dermatol 1994; 30:774-8.

5. Bath-Hextall FJ, Perkins W, Bong J et al. Interventions for basal cell carcinoma of the skin. Cochrane Database Syst Rev 2007: CD003412.

6. Karagas MR, McDonald JA, Greenberg ER et al. Risk of basal cell and squamous cell skin cancers after ionizing radiation therapy. For The Skin Cancer Prevention Study Group. J Natl Cancer Inst 1996; 88: 1848-53.

7. Ron E, Modan B, Preston D et al. Radiation-induced skin carcinomas of the head and neck. Radiat Res 1991; 125: 318-25.

8. Mseddi M, Bouassida S, Marrekchi S et al. [Basal cell carcinoma of the scalp after radiation therapy for tinea capitis: 33 patients]. Cancer Radiother 2004; 8: 270-3.

9. Hassanpour SE, Kalantar-Hormozi A, Motamed S et al. Basal cell carcinoma of scalp in patients with history of childhood therapeutic radiation: a retrospective study and comparison to nonirradiated patients. Ann Plast Surg 2006; 57: 509-12.

10. Mseddi $M$, Dammak $A$, Jellouli $M$ et al. [Profile of basal cell carcinomas of the scalp after radiotherapy for tinea capitis labout 63 cases)]. Rev Med Liege 2006; 61: 724-7.

11. Shore RE, Albert RE, Reed $M$ et al. Skin cancer incidence among children irradiated for ringworm of the scalp. Radiat Res 1984; 100: 192-204.

12. Shore RE, Moseson $M$, Xue $X$ et al. Skin cancer after X-ray treatment for scalp ringworm. Radiat Res 2002; 157: 410-8.

13. Karagas MR, Nelson HH, Zens MS et al. Squamous cell and basal cell carcinoma of the skin in relation to radiation therapy and potential modification of risk by sun exposure. Epidemiology 2007; 18: 776-84. 14. Raasch BA, Buettner PG, Garbe $C$. Basal cell carcinoma: histological classification and body-site distribution. $\mathrm{Br} J$ Dermatol 2006; 155: 401-7.

15. Vantuchová Y CR. Histological types of basal cell carcinoma. Scripta Medica (BRNO) 2006; 79 (5-6): 261-70.

16. Boaventura $P$, Soares $P$, Pereira $D$ et al. Head and neck lesions in a cohort irradiated in childhood for tinea capitis treatment. Lancet Infect Dis $2011 ; 11$ : 163-4.

17. Vintém JM, Guerreiro MD, Carvalho H. Desigualdades de género e sociais na saúde e doença em Portugal - Uma análise do Módulo "Saúde" do European Social Survey 2004. VI Congresso Português de Sociologia, 25-28 Junho de 2008 2008; №325.

18. Stang $A$, Ziegler $S$, Buchner $U$ et al. Malignant melanoma and nonmelanoma skin cancers in Northrhine-Westphalia, Germany: a patient- vs. diagnosis-based incidence approach. Int J Dermatol 2007; 46: 564-70.

19. Estrada JG. Non-melanoma skin cancer in Catalonia. A community-based prevalence study. Int J Dermatol 2005; 44: 922-4. 
20. Bariani RL, Nahas FX, Barbosa MV et al. Basal cell carcinoma: an updated epidemiological and therapeutically profile of an urban population. Acta Cir Bras 2006; 21 : 66-73.

21. Scrivener $Y$, Grosshans E, Cribier B. Variations of basal cell carcinomas according to gender, age, location and histopathological subtype. Br J Dermatol 2002; 147: $41-7$.

22. Meibodi NT, Maleki $M$, Javidi $Z$ et al. Clinicopathological evaluation of radiation induced basal cell carcinoma. Indian J Dermatol 2008; 53: 137-9.

23. Fazaa $B$, Cribier $B$, Zaraa I et al. Low-dose X-ray depilatory treatment induces trichoblastic tumors of the scalp. Dermatology 2007; 215: $301-7$

24. Maalej $M$, Frikha $H$, Kochbati L et al. Radio-induced malignancies of the scalp about 98 patients with 150 lesions and literature review. Cancer Radiother 2004; 8: 81-7.

25. Marin-Gutzke M, Sanchez-Olaso A, Berenguer B et al. Basal cell carcinoma in childhood after radiation therapy: case report and review. Ann Plast Surg 2004; 53: 593-5.
26. Bastiaens MT, Hoefnagel JJ, Bruijn JA et al. Differences in age, site distribution, and sex between nodular and superficial basal cell carcinoma indicate different types of tumors. J Invest Dermatol 1998; 110: 880-4.

27. Hakverdi S, Balci DD, Dogramaci CA et al. Retrospective analysis of basal cell carcinoma. Indian J Dermatol Venereol Leprol 2011; 77: 251.

28. Pelucchi C, Di Landro A, Naldi L et al. Risk factors for histological types and anatomic sites of cutaneous basal-cell carcinoma: an italian case-control study. J Invest Dermatol 2007; 127: 935-44.

29. Gallagher RP, Hill GB, Bajdik $C D$ et al. Sunlight exposure, pigmentary factors, and risk of nonmelanocytic skin cancer. I. Basal cell carcinoma. Arch Dermatol 1995; 131: 157-63.

30. Rosso $S$, Zanetti $R$, Pippione $M$ et al. Parallel risk assessment of melanoma and basal cell carcinoma: skin characteristics and sun exposure. Melanoma Res 1998; 8: 573-83.

31. Johnson ML, Johnson KG, Engel A. Prevalence, morbidity, and cost of dermatologic diseases. J Am Acad of Dermatol 1984; 11 : 930-6. 